\title{
Phase II trial of nab-paclitaxel in metastatic breast cancer patients with visceral metastases
}

Yizhao Xie ${ }^{1,2+}$, Chengcheng Gong ${ }^{1,2+}$, Jian Zhang ${ }^{1,2}$, Leiping Wang ${ }^{1,2}$, Jun Cao ${ }^{1,2}$, Zhonghua Tao ${ }^{1,2}$, Ting Li1 ${ }^{1,2}$, Yannan Zhao ${ }^{1,2}, \mathrm{Yi} \mathrm{Li}^{1,2}$, Shihui Hu ${ }^{1,2}$, Biyun Wang ${ }^{1,2^{*+}}$ and Xichun $\mathrm{Hu}^{1,2^{*+}}$

\begin{abstract}
Background: Visceral metastases account for $48-67 \%$ of metastatic breast cancer (MBC) patients and presage a worse overall survival. Previous study suggested potential effect of nab-paclitaxel on patients with visceral metastases subgroups. This phase II trial was conducted to explore the efficacy and safety of nab-paclitaxel in such a high-risk group of patients.

Methods: In this prospective, single-center, open-label, phase II study, MBC patients with visceral metastases ( $N=$ 80) received nab-paclitaxel (Abraxane, $125 \mathrm{mg} / \mathrm{m} 2, \mathrm{D} 1, \mathrm{D} 8, \mathrm{D} 15$ every 28 days).

Results: The median PFS was 5.1 months (95\% Cl: 4.2-6.0 months), with an ORR of 33.8\% (95\% Cl 21.3-43.8\%) and CBR of $66.2 \%$ (95\% CI 56.3-75.0\%). In univariate analysis, patients with premenopausal status had a trend of better treatment outcome. Multivariate analysis demonstrated non brain metastasis (adjusted HR $0.31,95 \% \mathrm{Cl} 0.12-0.83$, $P=0.019$ ) and first line treatment (adjusted HR $0.37,95 \% \mathrm{Cl} 0.17-0.81, P=0.013$ ) as independent predictors of longer PFS. The overall safety was acceptable with most common treatment-related, grade $\geq 3$ toxicities of neutropenia (16.3\%) and sensory neuropathy (3.7\%).

Conclusions: This phase II trial documented satisfactory efficacy and safety of nab-paclitaxel in MBC patients with visceral metastases, providing evidence for relative clinical practice. Patients in first line therapy had better treatment outcome. For patients with premenopausal status or brain metastasis, further alternatives (for example, combined chemotherapy or targeting therapy) might be required. This study also demonstrated the efficacy and safety of $125 \mathrm{mg} / \mathrm{m} 2$ nab-paclitaxel among Asian patients.
\end{abstract}

Trial registration: This research is registered under clinicaltrials.gov (NCT 02687490, February 22, 2016).

Keywords: Metastatic breast Cancer, Chemotherapy, Nab-paclitaxel

\footnotetext{
*Correspondence: wangbiyun0107@hotmail.com; huxichun2017@163.com

'Yizhao Xie, Chengcheng Gong, Biyun Wang and Xichun Hu contributed equally to this work.

'Department of Medical Oncology, Fudan University Shanghai Cancer Center, No.270, Dong'an Road, Xuhui District, Shanghai 200032, China

Full list of author information is available at the end of the article
}

C C The Author(s). 2021 Open Access This article is licensed under a Creative Commons Attribution 4.0 International License, which permits use, sharing, adaptation, distribution and reproduction in any medium or format, as long as you give appropriate credit to the original author(s) and the source, provide a link to the Creative Commons licence, and indicate if changes were made. The images or other third party material in this article are included in the article's Creative Commons licence, unless indicated otherwise in a credit line to the material. If material is not included in the article's Creative Commons licence and your intended use is not permitted by statutory regulation or exceeds the permitted use, you will need to obtain permission directly from the copyright holder. To view a copy of this licence, visit http://creativecommons.org/licenses/by/4.0/ The Creative Commons Public Domain Dedication waiver (http://creativecommons.org/publicdomain/zero/1.0/) applies to the data made available in this article, unless otherwise stated in a credit line to the data. 


\section{Introduction}

Among female malignancy, breast cancer (BC) remains the most common type and a primary cause of cancerrelated death worldwide, leading to nearly 464 thousand deaths per year, mostly for metastatic breast cancer (MBC) $[1,2]$. The incidence and mortality of breast cancer keep growing in China as well, according to epidemiologic study [3].

Visceral metastases were found in $48-67 \%$ patients with metastatic breast cancer $[4,5]$. Studies showed that patients with visceral metastases had worse treatment outcome and shorter overall survival (OS) compared to other MBC patients, suggesting that visceral metastasis was a highly poor prognostic factor in terms of breast cancer [4-7]. Furthermore, National Comprehensive Cancer Network $(\mathrm{NCCN})$ guideline recommends chemotherapy to luminal type $\mathrm{MBC}$ with visceral crisis [8].

Nanoparticle albumin-bound (nab)-paclitaxel is a biologically interactive, albumin-bound formation of paclitaxel particle developed to avoid or minimize the toxicities associated with traditional paclitaxel and docetaxel such as sensory neuropathy, neutropenia and severe hypersensitivity. Preclinical study showed that nabpaclitaxel had 33\% higher paclitaxel concentration to tumors and enhanced transport across endothelial cells compared to standard paclitaxel [9]. A phase III trial enrolled 454 MBC patients and randomized them into 3week cycles of either $260 \mathrm{mg} / \mathrm{m} 2$ nab-paclitaxel or 175 $\mathrm{mg} / \mathrm{m} 2$ standard paclitaxel, showing results of a significantly better overall response rate (ORR, 33\% vs 19\%; $P=0.001$ ), longer time to progression (TTP, 5.3 vs 3.9 months; $P=0.006$ ) and subgroup analysis showed a significant higher ORR in visceral disease patients of nabpaclitaxel group compared to standard group (34\% vs $19 \%, p=0.002)$, [10]. Another phase two trial explored three different nab-paclitaxel doses $(300 \mathrm{mg} / \mathrm{m} 2 \mathrm{q} 3 \mathrm{w}$, $100 \mathrm{mg} / \mathrm{m} 2$, or $150 \mathrm{mg} / \mathrm{m} 2 \mathrm{qw}$ ) and docetaxel $100 \mathrm{mg} /$ $\mathrm{m} 2 \mathrm{q} 3 \mathrm{w}$ for untreated patients with $\mathrm{MBC}$ and indicated that the $150 \mathrm{mg} / \mathrm{m} 2$ qw regimen of nab-paclitaxel showed extended progression free survival (PFS) than docetaxel (12.9 vs 7.5 months, $P=0.0065)$, with lower rate of grade $3 / 4$ neutropenia, febrile neutropenia, and fatigue, moreover, $84 \%$ patients in this trial had visceral metastases [11]. After permission by the drug administration, real world data also indicated safety and efficacy of nab-paclitaxel in clinical use [12, 13].

Since subgroup analysis indicated a potential positive effect of nab-paclitaxel in visceral metastasis patients, here we conducted a phase II clinical trial of nabpaclitaxel in $\mathrm{MBC}$ patients with visceral metastases. The present study aimed to explore the efficacy and safety of nab-paclitaxel in such a high-risk group of patients. We also explored the use of $125 \mathrm{mg} / \mathrm{m} 2$ nab-paclitaxel among Asian patients.

\section{Methods}

This prospective, single-center, open-label, phase II study was conducted in Fudan University Shanghai Cancer Center. The protocol and related materials were approved by the appropriate institutional review boards and independent ethics committees. All process of this study was incompliance with the Declaration of Helsinki and the relevant guidelines. All of the patients signed written informed consent forms before study. This research is registered under clinicaltrials.gov (NCT 02687490).

\section{Patients}

Eligible patients were nonpregnant, nonlactating 18 to 70 years old females with histologically or cytologically confirmed, measurable MBC with an expected survival of more than 12 weeks. Patients were included if they had radiologically or histologically confirmed visceral dominant metastases; were expected to acquire benefit from chemotherapy; received paclitaxel in metastatic setting should be proven effective to prior paclitaxel based regimen and disease progressed after at least 3 months from the last administration of paclitaxel; received paclitaxel as neoadjuvant/adjuvant therapy can be enrolled if disease relapsed after at least 6 months from the completion of neoadjuvant/adjuvant chemotherapy; had acceptable clinical laboratory test results at baseline.

Patients were excluded from participation if they had an Eastern Cooperative Oncology Group performance (ECOG) status of more than 2; received treatment with other experimental drug within 4 weeks before enrollment; received radiotherapy of axial bones within 4 weeks before enrollment or lack of recovery from prior radiotherapy; had symptomatic central nervous system metastases; had uncontrolled serious infection; or had other malignancy within the previous 5 years except nonmelanoma skin cancer, cervical intraepithelial neoplasia, or in situ cervical cancer.

\section{Treatments}

Patients were treated with nab-paclitaxel (Abraxane, 125 $\mathrm{mg} / \mathrm{m} 2$, D1, D8, D15 every 28 days) until disease progression (PD), death, unacceptable toxicity, or physician's decision. Combined treatments were allowed based on physician's choice, for instance, trastuzumab and bevacizumab.

\section{Assessments}

All patients included in the study were evaluated with appropriate cross sectional imaging studies for disease response at baseline and every 8 weeks. Complete response (CR), partial response (PR), stable disease (SD) and $\mathrm{PD}$ were defined and assessed according to the Response Evaluation Criteria in Solid Tumors (RECIST) 
1.1. CRs and PRs required subsequent confirmation of response at least 4 weeks later.

The primary efficacy measure was PFS; secondary efficacy measures were ORR, OS and safety. PFS was defined as the time from study registration to disease progression or death from any cause. OS was defined as the time from study registration to death from any cause. Safety was evaluated as adverse events (AEs) according to the National Cancer Institute Common Terminology Criteria for Adverse Events (CTCAE) version 4.03.

\section{Statistical analysis}

The planned enrollment for this study was at least 70 patients. The sample size of 70 would have provided an estimated PFS of 5 months, $80 \%$ power, with a two-sided type I and type II error of 0.05 .

Clinicopathologic characteristics was summarized in descriptive statistics. PFS and OS were estimated by the Kaplan-Meier method and the hazard ratios (HRs) and corresponding 95\% confidence intervals (CIs) were estimated using the Cox proportional harzard model. Exploratory analyses were performed with the log- rank test. Cox multivariate models were performed based on the univariate analyses results. CBR and ORR were calculated with their 95\% CI. Toxicities were summarized, and the maximum grade per patient was used as the summary measure. $P$ value less than 0.05 was considered statistically significant. All statistical analyses were managed using SPSS version 23.0.

\section{Results}

\section{Patients}

From March 2016 through September 2020, 80 patients were enrolled on this study and treated at Fudan University Shanghai Cancer Center. All patients received at least one dose of the study treatment and were considered evaluable for toxicity and response. The mean age of patients was 52 years (range 26-86). A majority of patients were estrogen receptor (ER)/progesterone receptor (PR) positive $(76.3 \%)$, while $22.5 \%$ patients were triple negative and 2 patients $(2.5 \%)$ were human epidermal growth factor 2 (HER2) positive. Most patients were in stable status (ECOG 0-1). Liver metastasis accounts for $67.5 \%$ patients, followed by lung metastasis (61.3\%) and brain metastasis $(6.3 \%)$. Patients usually had 3 or more metastasis sites (62.5\%). The median prior metastatic chemotherapy regimens were 2 lines. A small minority of patients received combined treatment together with nab-paclitaxel (15\%), mostly for targeting therapy, which was shown in Fig. 1. Baseline patient characteristics are summarized in Table 1.

\section{Efficacy}

The median PFS was 5.1 months (95\% CI: 4.2-6.0 months, Fig. 2). As for the best treatment response, there were $26(32.5 \%)$ patients with $\mathrm{PR}, 27(33.8 \%)$ patients with SD and 27(33.8\%) patients with PD, yielding an ORR of $33.8 \%$ (95\% CI 21.3-43.8\%) and CBR of $66.2 \%$ (95\% CI 56.3-75.0\%). Table 2 summarized the outcomes of patients treated on this protocol. The median OS were not reached at the time of analysis.

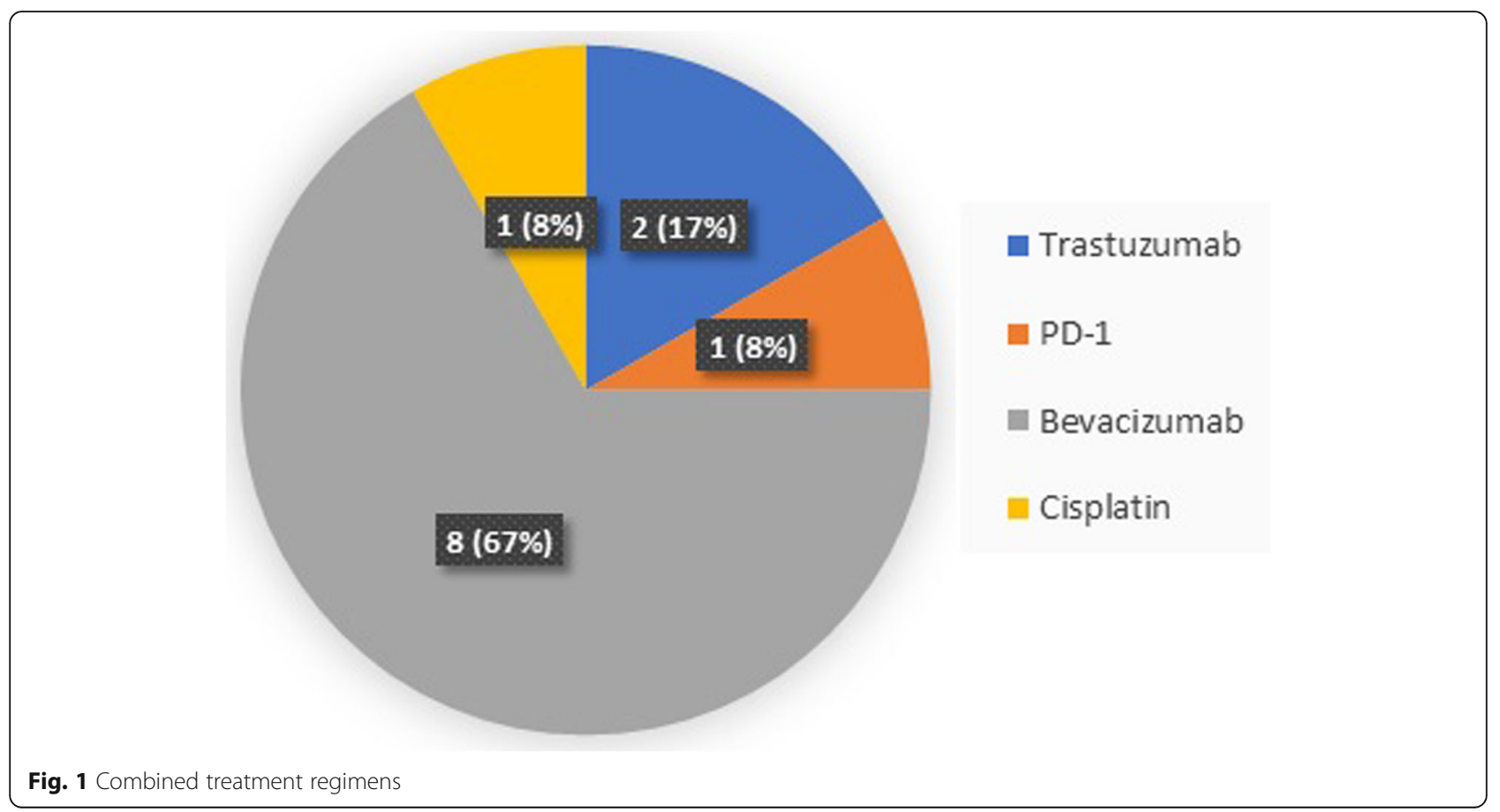


Table 1 Patient characteristics at baseline

\begin{tabular}{|c|c|c|}
\hline Characteristics & $\begin{array}{l}\text { Total } \\
N=80\end{array}$ & $\begin{array}{l}\text { Percentage } \\
\%\end{array}$ \\
\hline Median Age (range) & $52(26-86)$ & \\
\hline \multicolumn{3}{|l|}{ ER/PR/HER2 status } \\
\hline ER and/or PR positive & 61 & 76.3 \\
\hline ER and PR negative & 19 & 23.7 \\
\hline HER2 positive & 2 & 2.5 \\
\hline HER2 negative & 78 & 97.5 \\
\hline Triple negative & 18 & 22.5 \\
\hline \multicolumn{3}{|l|}{ ECOG } \\
\hline $0-1$ & 77 & 96.2 \\
\hline$\geq 2$ & 3 & 3.8 \\
\hline \multicolumn{3}{|l|}{ Menopausal status } \\
\hline Premenopausal & 22 & 27.5 \\
\hline Postmenopausal & 58 & 72.5 \\
\hline \multicolumn{3}{|l|}{ Metastatic sites } \\
\hline Lung & 49 & 61.3 \\
\hline Liver & 54 & 67.5 \\
\hline Brain & 5 & 6.3 \\
\hline \multicolumn{3}{|l|}{ Number of metastatic sites } \\
\hline $1-2$ & 30 & 37.5 \\
\hline$\geq 3$ & 50 & 62.5 \\
\hline Prior metastatic chemotherapy regimens & Median: 2 (Range 0-8) & \\
\hline 0 & 30 & 37.5 \\
\hline 1 & 22 & 27.5 \\
\hline$\geq 2$ & 28 & 35 \\
\hline \multicolumn{3}{|l|}{ Combined Treatment } \\
\hline Yes & 12 & 15 \\
\hline No & 68 & 85 \\
\hline
\end{tabular}

In subset analysis, the median PFS according to molecular types was 5.1 (95\% CI 4.2-6.0) months for luminal and 4.1 months $(95 \%$ CI $1.5-6.7)$ for TNBC $(p=$ 0.8 , Fig. 3A). The median PFS of HER2+ patients was not available due to sample size. Patients receiving nabpaclitaxel as first line had longer PFS compared to later lines [mPFS 12.5 months (95\% CI:3.8-21.1) versus 4.6 months (95\% CI:3.7-5.5), $P=0.007$, Fig. 3B]. Patients with brain metastasis showed poorer outcome compared to others [2.8 months (95\% CI:1.0-4.6) versus 5.1 months (95\% CI: 4.3-5.9), $P=0.004$, Fig. 3C]. Postmenopausal women had a trend of longer PFS (5.4 months, 95\% CI 3.9-6.8) in comparison with premenopausal women (3.6 months, 95\% CI 1.3-5.8, $P=$ 0.051, Fig. 3D). No significant difference or trend of PFS was observed in patients receiving combined treatment or not; age over 65 or not; had over 3 metastatic sites or not $(P>0.1)$.
Multivariate analysis demonstrated non brain metastasis (adjusted HR 0.31, 95\% CI 0.12-0.83, $P=0.019$ ) and first line treatment (adjusted HR 0.37, 95\% CI 0.17-0.81, $P=0.013)$ as independent predictors of longer PFS.

\section{Safety}

The most common treatment-related, grade $\geq 2$ toxicities were neutropenia (42.5\%), sensory neuropathy $(18.8 \%)$, fatigue (6.2\%), leukopenia (6.2\%), arthralgia/myalgia (5\%) and diarrhea (5\%). Lung infection was seen in 2 patients (2.5\%), which might be owing to neutropenia. Skin rash occurred in 2 patients $(2.5 \%)$ probably because of allergy. Grade 4 hematologic toxicities were observed in 8 patients (10\%). Only one patient (1.2\%) developed grade 4 sensory neuropathy. Table 3 summarized the grade 2 and greater toxicities observed in this study thought to be possibly, probably or definitely related to the study treatment. 


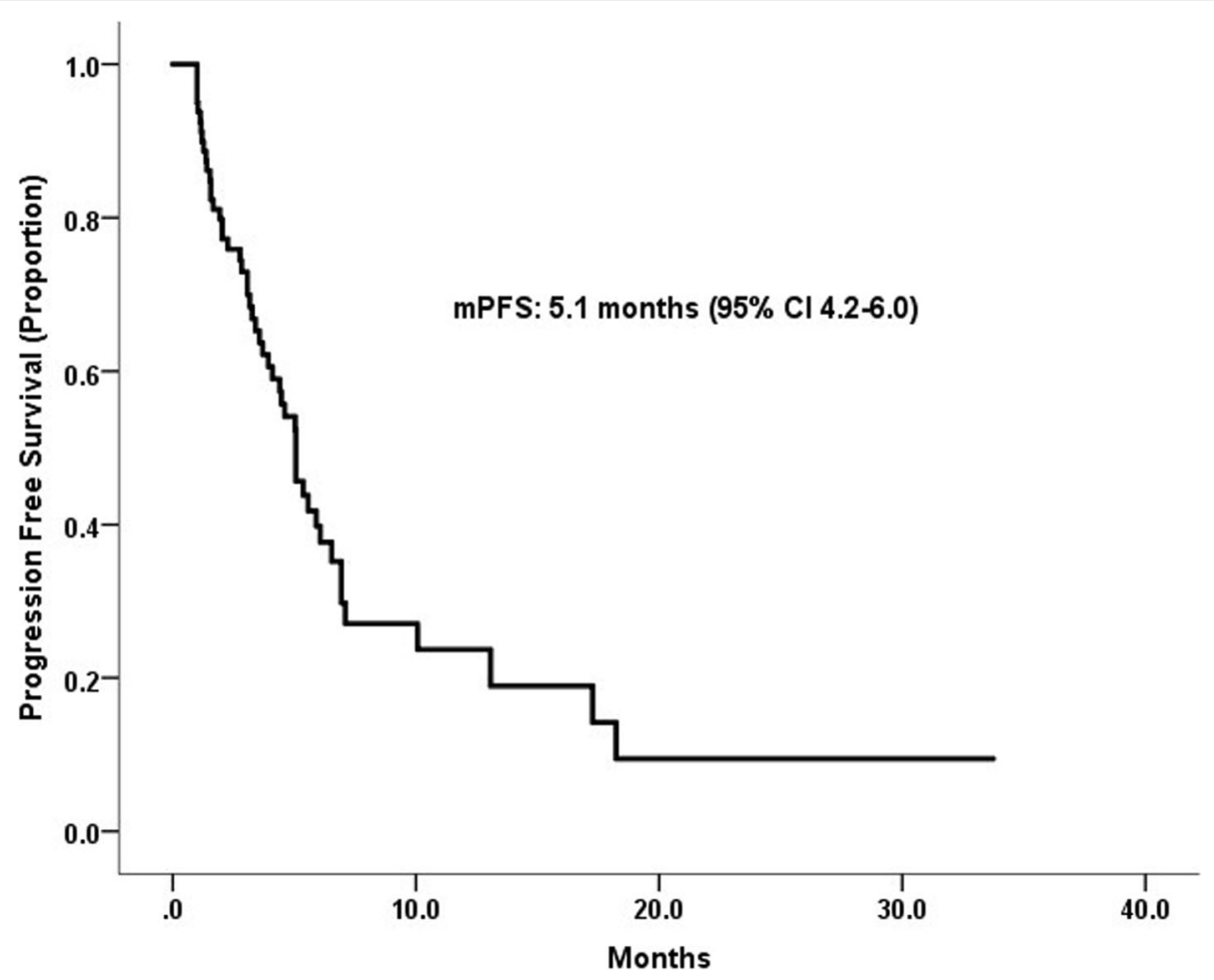

Fig. 2 Kaplan-Meier curves for progression-free survival

\section{Discussion}

In this prospective, phase II trial, we examined the efficacy and safety of nab-paclitaxel in MBC patients with visceral metastases. To the best of our knowledge, this is the first direct investigation of nab-paclitaxel in MBC patients with visceral dominant metastases.

We reported a mPFS of 5.1 months and ORR of 33.8\%, which conformed to previous studies on nab-paclitaxel for different lines of MBC patients (mPFS 5.75 months, ORR $33 \%$ ), despite of limitation of visceral metastases [10]. Other studies explored nab-paclitaxel as first line treatment demonstrated a mPFS of 7.1-12.9 months, which could be attributed to first line treatment as well as nonselection of visceral metastasis [11, 14]. With regards to novel chemotherapy eribulin, a phase III trial indicated a mPFS of 4.1 months when treating MBC patients

Table 2 Summary of best overall patient response

\begin{tabular}{lll}
\hline Response & $\begin{array}{l}\boldsymbol{N = 8 0} \\
(\%)\end{array}$ & $\mathbf{9 5 \% ~ C l}$ \\
\hline Complete response & $0(0)$ & \\
Partial response & $26(32.5)$ & \\
Stable disease & $27(33.8)$ & \\
Progressive disease & $27(33.8)$ & $21.3-43.8$ \\
ORR\% & 33.8 & $56.3-75.0$ \\
CBR\% & 66.2 & \\
\hline
\end{tabular}

pretreated with anthracycline- and taxane-based therapy, which was similar in comparison to our data [15]. As for targeting therapy of luminal type disease, investigators explored the Palbociclib plus endocrine therapy in patients with visceral metastases and showed a mPFS of 9.2 months for patients with prior resistance to endocrine therapy, which was prolonged possibly owing to ER/PR positive disease and chemotherapy naive for metastatic pattern [5]. Furthermore, this study explored the use of $125 \mathrm{mg} / \mathrm{m} 2$ nab-paclitaxel among Asian patients. In all, our data showed a pleasant treatment result of nabpaclitaxel for patients with visceral metastases.

In univariate analysis, although luminal type had higher mPFS value, no significant difference was observed between luminal type and TNBC, which could be attributed to limited sample size of TNBC and heavy pre-treatments. Interestingly, we observed a trend of longer PFS in premenopausal patients compared to postmenopausal women, and we consider a relative younger age to be a possible cause. Partidge et al. conducted a prognosis study enrolling 17,575 breast cancer patients and indicated a significant worse treatment outcome of patients less than 40 years old in contrast with elder patients [16]. Therefore, we recommended young patients to receive more aggressive treatment regimens if possible. Statistical difference was not found between combined treatment and monotherapy, mainly because of a limited sample size. 


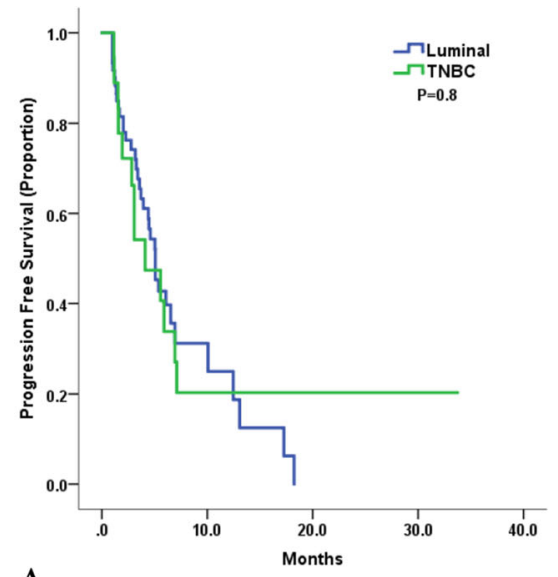

A

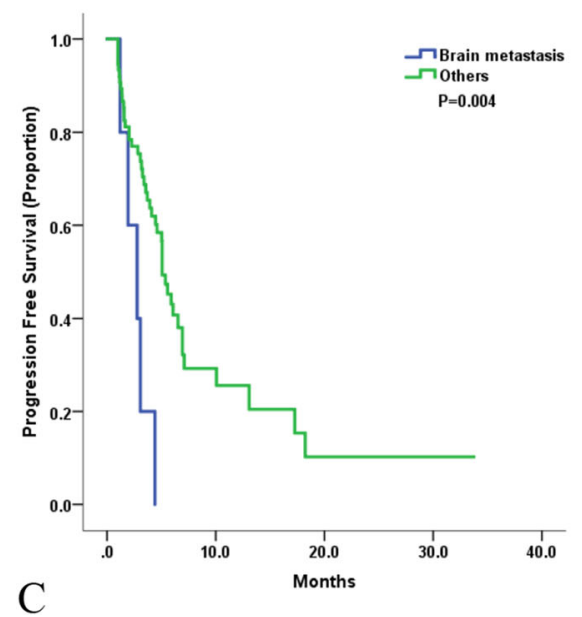

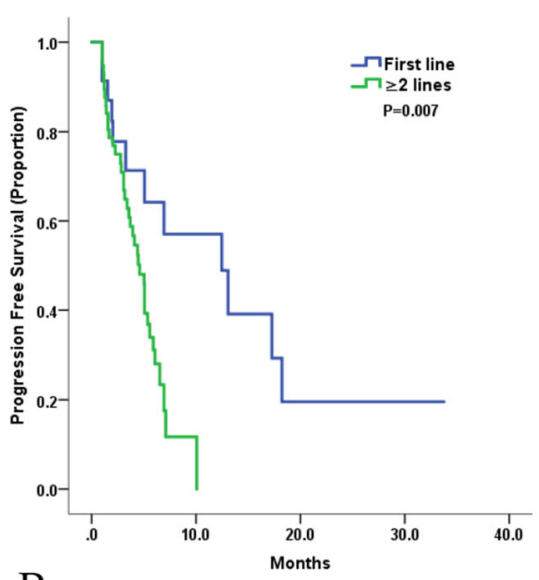

B

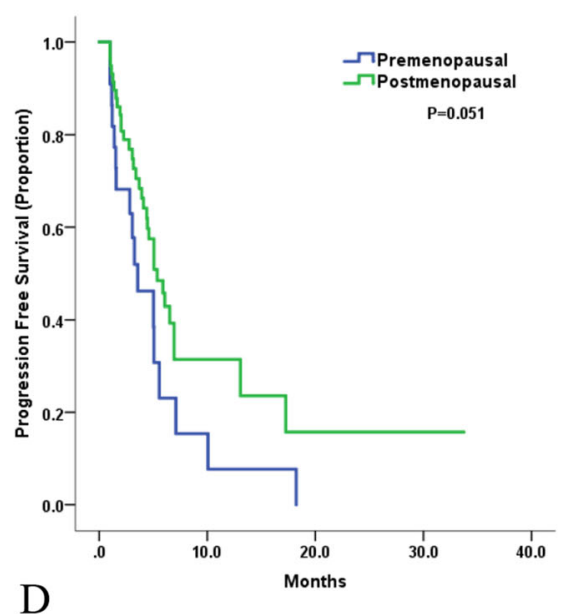

Fig. 3 Kaplan-Meier curves for progression-free survival by: A. Molecular types B. Treatment lines C. Brain metastasis or not D. Menopausal status

Non brain metastasis and first line treatment appeared to predict greater PFS even after balancing the known factors. We have discussed the superiority of first line therapy before, which was also demonstrated by clinical and observational trials $[10,12]$. Paclitaxel has limited effect on brain metastasis probably due to constrained efflux transport mechanisms present at the blood brain barrier, which leads to a sub-therapeutic and nonuniform drug concentrations in brain metastatic tumor $[17,18]$. Although nab-paclitaxel showed an increased

Table 3 Summary of grade 2 and greater toxicities

\begin{tabular}{|c|c|c|c|c|}
\hline \multirow[t]{2}{*}{ Adverse events (\%) } & \multicolumn{4}{|c|}{ Toxicity grade $(N=80)$} \\
\hline & Grade 2 & Grade 3 & Grade 4 & All \\
\hline Neutropenia & $21(26.2)$ & $6(7.5)$ & $7(8.8)$ & $34(42.5)$ \\
\hline Sensory Neuropathy & $12(15)$ & $2(2.5)$ & $1(1.2)$ & $15(18.8)$ \\
\hline Fatigue & $5(6.2)$ & 0 & 0 & $5(6.2)$ \\
\hline Arthralgia / Myalgia & $4(5)$ & 0 & 0 & $4(5)$ \\
\hline Diarrhea & $1(1.2)$ & $3(3.8)$ & 0 & $4(5)$ \\
\hline Leukopenia & $4(5)$ & 0 & $1(1.2)$ & $5(6.2)$ \\
\hline Elevated alanine aminotransferase & $2(2.5)$ & 0 & 0 & $2(2.5)$ \\
\hline Infection & $2(2.5)$ & 0 & 0 & $2(2.5)$ \\
\hline Rash & $2(2.5)$ & 0 & 0 & $2(2.5)$ \\
\hline
\end{tabular}


brain uptake and toxicity against P-glycoprotein expressing cancer cells of a rat model, clinical trials did not report a positive result [19]. Thus, certain treatment of brain metastasis remained controversial.

The toxicity profile indicated a comparable result to previous studies, with most frequent grade 3/4 AE of neutropenia and sensory neuropathy $[10,11]$. Although 3 patients reduced treatment dose because of dose limiting toxicities, the overall safety was acceptable considering a cytotoxic drug. Notably, 3 patients developed unusual grade 3 diarrhea, which could be attributed to individual difference and all patients were relieved after use of loperamide.

\section{Conclusions}

In conclusion, this phase II trial documented satisfactory efficacy and safety of nab-paclitaxel in MBC patients with visceral metastases, providing evidence for relative clinical practice. Patients in first line therapy had better treatment outcome than later lines. For patients with premenopausal status or brain metastasis, further alternatives (for example, combined chemotherapy or targeting therapy) might be required. This study also demonstrated the efficacy and safety of $125 \mathrm{mg} / \mathrm{m} 2 \mathrm{nab}-$ paclitaxel among Asia patients.

\section{Abbreviations}

MBC: Metastatic breast cancer; HER2: Human epidermal growth factor receptor 2; OS: Overall survival; HR: Hazard ratio; Cl: Confidence interval; NCCN: National Comprehensive Cancer Network; RECIST: Response Evaluation Criteria in Solid Tumors; DFI: Disease-free interval; CTCAE: Common Terminology Criteria for Adverse Events; SPSS: Statistical Product and Service Solutions

\section{Acknowledgements}

The authors would like to thank patients, nurses and clinicians for their participation in this study.

\section{Authors' contributions}

Yizhao Xie collected all of the data from database, performed statistical analysis, and finished the manuscript. Chengcheng Gong participated in the manuscript and checked the English grammars in manuscript. Jian Zhang, Leiping Wang, Zhonghua Tao and Ting Li participated in the enrollment and treatment of patients. Yannan Zhao, Yi Li and Shihui Hu participated in the visiting of patients. Biyun Wang and Xichun Hu designed, carried out the study and revised the manuscript. The authors read and approved the final manuscript.

\section{Funding}

This work was supported by grants from National Natural Science Foundation of China (81874114).

\section{Availability of data and materials}

The datasets generated and/or analyzed during the current study are not publicly available due to hospital policy but are available from the corresponding author on reasonable request.

\section{Declarations}

\section{Ethics approval and consent to participate}

All procedures performed in studies involving human participants were in accordance with the ethical standards of the institutional research committee and with the 1964 Helsinki declaration and its later amendments or comparable ethical standards. All of the patients signed written informed consent forms before study. The study has been approved from Institutional Review Board of Fudan University Cancer Hospital.

\section{Consent for publication}

Not applicable.

\section{Competing interests}

The authors declare that they have no conflict of interest.

\section{Author details}

'Department of Medical Oncology, Fudan University Shanghai Cancer Center, No.270, Dong'an Road, Xuhui District, Shanghai 200032, China. ${ }^{2}$ Department of Oncology, Shanghai Medical College, Fudan University, Shanghai, China.

Received: 2 April 2021 Accepted: 27 October 2021

Published online: 02 November 2021

\section{References}

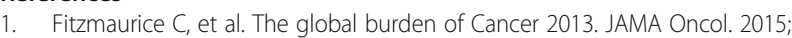
1(4):505-27. https://doi.org/10.1001/jamaoncol.2015.0735.

2. Bray F, Ferlay J, Soerjomataram I, Siegel RL, Torre LA, Jemal A. Global cancer statistics 2018: GLOBOCAN estimates of incidence and mortality worldwide for 36 cancers in 185 countries. CA Cancer J Clin. 2018;68(6):394-424. https://doi.org/10.3322/caac.21492.

3. Chen W, Zheng R, Baade PD, Zhang S, Zeng H, Bray F, et al. Cancer statistics in China, 2015. CA Cancer J Clin. 2016;66(2):115-32. https://doi.org/10.3322/ caac.21338.

4. Gobbini E, Ezzalfani M, Dieras V, Bachelot T, Brain E, Debled M, et al. Time trends of overall survival among metastatic breast cancer patients in the real-life ESME cohort. Eur J Cancer. 2018;96:17-24. https://doi.org/10.1016/j. ejca.2018.03.015

5. Turner NC, Finn RS, Martin M, Im SA, DeMichele A, Ettl J, et al. Clinical considerations of the role of palbociclib in the management of advanced breast cancer patients with and without visceral metastases. Ann Oncol. 2018:29(3):669-80. https://doi.org/10.1093/annonc/mdx797.

6. Lee ES, Jung SY, Kim JY, Kim JJ, Yoo TK, Kim YG, et al. Identifying the potential long-term survivors among breast cancer patients with distant metastasis. Ann Oncol. 2016;27(5):828-33. https://doi.org/10.1093/annonc/ mdw036.

7. Solomayer EF, Diel IJ, Meyberg GC, Gollan C, Bastert G. Metastatic breast cancer: clinical course, prognosis and therapy related to the first site of metastasis. Breast Cancer Res Treat. 2000;59(3):271-8. https://doi.org/10.1 023/A:1006308619659.

8. Gradishar WJ, Anderson BO, Abraham J, Aft R, Agnese D, Allison KH, et al. Breast Cancer, Version 3.2020, NCCN Clinical Practice Guidelines in Oncology. J Natl Compr Canc Netw. 2020;18(4):452-78. https://doi.org/10. 6004/jnccn.2020.0016.

9. Desai N, Trieu V, Yao Z, Louie L, Ci S, Yang A, et al. Increased antitumor activity, intratumor paclitaxel concentrations, and endothelial cell transport of cremophor-free, albumin-bound paclitaxel, ABI-007, compared with cremophor-based paclitaxel. Clin Cancer Res. 2006;12(4):1317-24. https://doi. org/10.1158/1078-0432.CCR-05-1634.

10. Gradishar WJ, Tjulandin S, Davidson N, Shaw H, Desai N, Bhar P, et al. Phase III trial of nanoparticle albumin-bound paclitaxel compared with polyethylated castor oil-based paclitaxel in women with breast cancer. Clin Oncol. 2005;23(31):7794-803. https://doi.org/10.1200/JCO.2005.04.937.

11. Gradishar WJ, Krasnojon D, Cheporov S, Makhson AN, Manikhas GM Clawson A, et al. Significantly longer progression-free survival with nabpaclitaxel compared with docetaxel as first-line therapy for metastatic breast cancer. J Clin Oncol. 2009;27(22):3611-9. https://doi.org/10.1200/JCO.2008.1 8.5397.

12. Liang C, Li L, Fraser CD, Ko A, Corzo D, Enger C, et al. The treatment patterns, efficacy, and safety of nab (R))-paclitaxel for the treatment of metastatic breast cancer in the United States: results from health insurance claims analysis. BMC Cancer. 2015;15(1):1019. https://doi.org/10.1186/s12885015-2027-x.

13. Koumarianou A, Makrantonakis P, Zagouri F, Papadimitriou C, Christopoulou A, Samantas E, et al. ABREAST: a prospective, real-world study on the effect of nab-paclitaxel treatment on clinical outcomes and quality of life of 
patients with metastatic breast cancer. Breast Cancer Res Treat. 2020;182(1): 85-96. https://doi.org/10.1007/s10549-020-05677-4.

14. Robert NJ, Diéras V, Glaspy J, Brufsky AM, Bondarenko I, Lipatov ON, et al. RIBBON-1: randomized, double-blind, placebo-controlled, phase III trial of chemotherapy with or without bevacizumab for first-line treatment of human epidermal growth factor receptor 2-negative, locally recurrent or metastatic breast cancer. J Clin Oncol. 2011;29(10):1252-60. https://doi.org/1 $0.1200 / \mathrm{JCO} .2010 .28 .0982$

15. Kaufman PA, Awada A, Twelves C, Yelle L, Perez EA, Velikova G, et al. Phase III open-label randomized study of eribulin mesylate versus capecitabine in patients with locally advanced or metastatic breast cancer previously treated with an anthracycline and a taxane. J Clin Oncol. 2015;33(6):594601. https://doi.org/10.1200/JCO.2013.52.4892.

16. Partridge AH, Hughes ME, Warner ET, Ottesen RA, Wong YN, Edge SB, et al. Subtype-Dependent Relationship Between Young Age at Diagnosis and Breast Cancer Survival. 2016;34(27):3308-14. https://doi.org/10.1200/JCO.201 5.65.8013.

17. Lockman PR, Mittapalli RK, Taskar KS, Rudraraju V, Gril B, Bohn KA, et al. Heterogeneous blood-tumor barrier permeability determines drug efficacy in experimental brain metastases of breast cancer. Clin Cancer Res. 2010; 16(23):5664-78. https://doi.org/10.1158/1078-0432.CCR-10-1564.

18. Loscher W, Potschka H. Role of drug efflux transporters in the brain for drug disposition and treatment of brain diseases. Prog Neurobiol. 2005;76(1):2276. https://doi.org/10.1016/j.pneurobio.2005.04.006.

19. Shah N, Mohammad AS, Saralkar P, Sprowls SA, Vickers SD, John D, et al. Investigational chemotherapy and novel pharmacokinetic mechanisms for the treatment of breast cancer brain metastases. Pharmacol Res. 2018;132: 47-68. https://doi.org/10.1016/j.phrs.2018.03.021.

\section{Publisher's Note}

Springer Nature remains neutral with regard to jurisdictional claims in published maps and institutional affiliations.

Ready to submit your research? Choose BMC and benefit from:

- fast, convenient online submission

- thorough peer review by experienced researchers in your field

- rapid publication on acceptance

- support for research data, including large and complex data types

- gold Open Access which fosters wider collaboration and increased citations

- maximum visibility for your research: over $100 \mathrm{M}$ website views per year

At $\mathrm{BMC}$, research is always in progress.

Learn more biomedcentral.com/submissions 